\title{
Predicting Transmembrane Pressure Rise from Biofouling Layer Compressibility and Permeability
}

\author{
Samuel J Skinner, Anthony D Stickland and Peter J Scales* \\ Particulate Fluids Processing Centre, Department of Chemical and Biomolecular Engineering, The \\ University of Melbourne, Parkville 3010, Australia \\ *peterjs@unimelb.edu.au
}

\begin{abstract}
The operation of filtration membranes for wastewater treatment is severely affected by biofouling formation, which causes a rapid increase in transmembrane pressure (TMP) in constant rate filtration. The TMP rise is often attributed to particulate fouling within the membrane, but the external fouling layer or filter cake contributes significantly. The fouling is highly compressible, so any model must incorporate cake compression. A one-dimensional controlled rate model based on compressible cakes and accurate sludge properties is proposed to predict the TMP rise needed to maintain constant flux. Increased compressibility results in more rapid TMP rise. Model predictions were compared to pilot-plant data and showed good correlation, without assuming fouling within the membrane. Optimization of cycle times and flux rates are performed.
\end{abstract}

\section{KEYWORDS}

Filter Cake, Fouling, Microfiltration, Modeling, Wastewater

\section{Introduction}

Microfiltration has become an essential stage in wastewater treatment for producing high quality water whilst maintaining a small footprint. The membrane bioreactor (MBR) is a promising example of a small footprint technology that uses wastewater filtration. A key problem for these devices is membrane bio-fouling, which reduces the output rate of purified water and increases the capital and operating costs. This fouling layer is highly compressible [1-4] and consolidates under applied differential pressure [5]. Many microfiltration devices operate under constant flux conditions, so the applied pressure is continually increased to overcome the rising resistance from the fouling layer. The applied pressure difference, or transmembrane pressure (TMP), is usually non-linear and increases rapidly triggering the need for frequent cleaning cycles.

Three distinct types of membrane fouling are prevalent in the literature [6]:

- Pore-blocking (internal to membrane)

- Pore constriction (internal to membrane)

- Cake fouling (external to membrane)

The particulate fouling internal to the membrane can contribute significantly to the hydrodynamic resistance to filtration [7]. However, a better appreciation of the effect of internal fouling can be obtained through an accurate representation of the compressibility and permeability of the external fouling layer.

This is the author manuscript accepted for publication and has undergone full peer review but has not been through the copyediting, typesetting, pagination and proofreading process, which may lead to differences between this version and the Version of Record.

Please cite this article as doi: 10.1002/ceat.201700117

This article is protected by copyright. All rights reserved. 
The rapid increase in TMP, or "TMP jump", has been attributed to both internal and external fouling, where it is often related to different fouling rates across the membrane [8]. This results in increased fluxes in less fouled areas and a subsequent rapid increase in the fouling rate of those regions, causing a sudden rise in TMP. The models proposed for the mechanism, or combination of mechanisms, to explain such behavior include [9]:

- Inhomogeneous pore fouling (pore narrowing [10] and pore loss [11])

- Inhomogeneous cake fouling (area loss) [12]

- Inhomogeneous fibre bundle [13]

As wastewater treatment sludges are heterogeneous mixtures of many components, the fouling layer is not uniform in depth or composition [14]. Because inhomogeneity can explain sharp TMP increase, there has been little attention on how a highly compressible fouling layer can cause rapid increase in TMP (see Fig. 1).

((Figure 1))

Initially, the pressure difference increases slowly, mainly due to accumulation of solids at the membrane surface. As the TMP increases, the networked fouling layer consolidates into a denser structure that is at higher solids volume fraction. This more compact structure increases the permeation drag (or resistance to filtration) and a greater pressure differential is required to maintain constant flux. The TMP continues to rise due to both the increased drag associated with accumulation of solids and compaction of the biofouling structure. The compression effects eventually dominate mass accumulation effects and a sharper increase in TMP rise is observed. Thus, the compressive strength and permeability of the biofouling network have a strong impact on the consequent increase in TMP.

Hermanowicz [15] used percolation theory to demonstrate that a rapid increase in TMP is predicted during compression of the suspension network structure within the filter cake. Furthermore, the rate of TMP increase has been shown to depend on the level of compressibility [16]. Systematic investigations into the effect of both the fouling layer permeability and compressibility on TMP jump are lacking from the literature, despite cake compression being an important consideration in wastewater filtration $[1,2,15,17,18]$.

Compressibility in filtration is defined such that the filter cake porosity and permeability are functions of the applied pressure $[4,19]$. As the bio-fouling layer is extremely compressible, any model of filtration must properly account for compressibility effects [20]. One such approach is "compressive rheology" from the studies of Buscall, White and Landman [21, 22]. The compressive strength, $p_{y}(\phi)$, determines the extent of filtration using the solids volume fraction, $\phi$, as the measure of solids concentration. The hindered settling function, $R(\phi)$, is a measure of the interphase hydrodynamic drag and determines the filtration rate. $R(\phi)$ is proportional to specific cake resistance and inversely proportional to the Darcian permeability. These dewatering material functions can be extracted from laboratory-scale gravity settling [23], centrifugation [22] and filtration [5] tests.

The material properties, $p_{y}(\phi)$ and $R(\phi)$, can be used to predict the sludge behavior in dewatering devices, provided that a model of the device has been developed and there are negligible shear forces in the device, or more specifically for MBRs, in the region of the fouling layer. Many sewage sludges have been characterized from laboratory-scale tests $[5,24]$ and have been successfully used to predict performance in filtration devices $[25,26]$. A similar approach to compressive rheology that uses local solids concentration dependent properties has previously been used to accurately model 
constant pressure membrane filtration of sludge in a MBR [1, 2]. However, the compressive rheology framework has never been applied to model constant rate filtration and backwashing. This work will provide the initial steps towards a comprehensive MBR model.

The aim of this study was to investigate the effect of compressibility and permeability of the external fouling layer during constant flux operation of a microfiltration device. This work explored how rapid TMP increase is expected under certain conditions. The model predictions were also compared to operating data from a pilot-plant developed to treat wastewater effluent to demonstrate that fouling layer compressibility and permeability can describe TMP rise.

\section{Theory}

\section{Microfiltration Device Modeling}

A new model has been developed to represent the operation of a microfiltration device, such as a MBR, based on a constant rate stage followed by a backwash stage (as shown in Fig. 2). During the constant rate phase, the feed flux, $q_{\text {feed }}$, is equal to the filtrate flux, $q$, and enters at a constant feed solids concentration, $\phi_{0}$.

((Figure 2))

The filtration surface is assumed to be permeable to water but impermeable to suspended solids and therefore the model makes no predictions of the performance of different membranes.

The backwash rate, $q_{B}$, is significantly higher than $q$ and is generally assumed to remove the fouling layer. The model allows for an irreversible fouling layer to be specified. The backwash sequence delivers a set volume of water at a constant rate. In general, around 10 backwashes are required before chemical cleaning [8]. The fill and chemical cleaning stages, as well as long term maintenance and operations within the batch cycle are not shown in the subsequent modeling. While it would be straightforward to incorporate a scheduled cleaning regime, this is not studied in this work.

\section{One-Dimensional Filtration Modeling}

The typical functional forms for the compressive strength from Stickland, et al. [27] and permeability from Usher, et al. [28] were used for this work (see Eq. (1) and Eq. (2) respectively). These forms were selected to highlight the impact of variation of material compressibility and permeability on filtration behavior.

$$
\begin{aligned}
& p_{y}(\phi)=\left\{\begin{array}{ll}
0 & : \phi<\phi_{g} \\
p_{y}(\phi)=p_{1}\left(\left(\frac{\phi}{\phi_{g}}\right)^{p_{2}}-1\right) & : \phi \geq \phi_{g}
\end{array}\right\} \\
& R(\phi)=r_{a}\left(\phi-r_{g}\right)^{r_{n}}+r_{b}
\end{aligned}
$$

where $p_{1}$ and $p_{2}$ are fitting parameters for compressibility data and $r_{\mathrm{a}}, r_{\mathrm{b}}, r_{\mathrm{g}}$ and $r_{\mathrm{n}}$ are used to fit the permeability data. The gel point, $\phi_{g}$, is the solids volume fraction at which a particulate network first forms. These material functions were then used as inputs to a one-dimensional model of filtration. In this model, the constant flux filtration process is simplified to a single dimension, $z$. The origin is at the membrane and $h_{0}$ is at the membrane outer wall (see Fig. 3). The feed is assumed to enter at a 
plane where $z=h_{0}$, with a feed concentration below $\phi_{\mathrm{g}}$ as the operational data from the pilot-plant indicated that the feed was dilute.

\section{((Figure 3))}

The numerical model is based on a fixed-width plate-and-frame press model [26], which builds on a model for piston-driven filtration [21]. For an initially un-networked suspension $\left(\phi_{0}<\phi_{\mathrm{g}}\right)$ under an applied differential pressure, there are three regions of interest. At $z=0$, the membrane surface is assumed to provide a constant resistance, $R_{m}$, so the pressure drop across the membrane is constant using Darcy's Law. The second region $\left(0<z<z_{c}(t)\right)$ increases in height with filtration time as the fouling layer develops at the membrane surface. The top of the forming cake, $z_{c}(t)$, is at $\phi_{g}$ and the solids pressure is zero. Between the top of the sludge network and the membrane outer wall $\left(z_{c}(t)<\right.$ $\left.z<h_{0}\right)$, the sludge remains at the initial concentration.

During constant flux operation, the average volume fraction, $\phi_{\text {ave, }}$ in the entire device is given by a global volumetric balance, where the flux, $q=\mathrm{d} V / \mathrm{d} t$, and $V$ is the specific volume of filtrate.

$$
\phi_{\text {ave }} h_{0}=\phi_{0}\left(q t+h_{0}\right)=\int_{0}^{h_{0}} \phi d z
$$

Eq. (4) is the governing equation to describe the 1D compressive dewatering, which was derived from volume and momentum balances [22].

$$
\frac{\partial \phi}{\partial t}=\frac{\partial}{\partial z}\left[D(\phi) \frac{\partial \phi}{\partial z}+\phi q\right]
$$

where gravitational acceleration is assumed to be negligible and $D(\phi)$ is the solids diffusivity, which is related to $R(\phi)$ and $p_{y}{ }^{\prime}(\phi)$ :

$$
D(\phi)=\frac{d p_{y}}{d \phi} \frac{(1-\phi)^{2}}{R(\phi)}
$$

The initial conditions at the start of constant flux operation are:

$$
\begin{aligned}
& \phi(z, 0)=\phi_{0} \\
& V(0)=0
\end{aligned}
$$

The solids pressure at the membrane is the applied pressure minus the pressure drop across the membrane caused by $R_{m}[21,26]$. The solids concentration at the membrane is determined using Eq. (7):

$$
p_{y}(\phi(0, t))=\Delta P(t)-R_{m} q
$$

where $\Delta P(t)$ is the variation in TMP with time. The concentration gradient at the membrane is given by Eq. (8). This equation assumes that the membrane rejects all solids, thus the solids velocity is zero.

$$
\left.\frac{\partial \phi}{\partial z}\right|_{z=0}=-q \frac{\phi(0, t)}{D(\phi(0, t))}
$$

The feed concentration is assumed to be constant, providing a boundary condition at the feed plane $\left(\phi\left(h_{0}, t\right)=\phi_{0}\right)$. These initial and boundary conditions allow the governing equation (Eq. (4)) to be 
solved with a $4^{\text {th }}-5^{\text {th }}$ order adaptive Runge-Kutta numerical algorithm. $\Delta P(t)$ and $\phi(z, t)$ are calculated for inputs of $h_{0}, \phi_{0}, p_{y}(\phi), D(\phi)$ and $q$.

\section{Optimization of Microfiltration Device Operation}

The basis for optimization was the filter area, $A$, required to achieve a given overall throughput, $Q$, compared with the throughput during the filtration stage, $q$. As the filtrate was used to backwash the membranes, the overall throughput is given by Eq. (9).

$$
Q=\frac{n A\left(V_{F}-V_{B}\right)}{n\left(t_{F}+t_{B}\right)}=\frac{A\left(q t_{F}-q_{B} t_{B}\right)}{t_{F}+t_{B}}
$$

where $t_{F}$ and $t_{B}$ are the filtration and backwash times for one cycle. $V_{F}$ and $V_{B}$ are the specific filtrate and backwash volumes. Note that $q_{B} t_{B} A$ is the backwash tank volume. The number of cycles, $n$, does not influence the calculated area as no irreversible fouling is assumed. The required filter area to give a desired overall throughput is therefore:

$$
A=\frac{Q\left(t_{F}+t_{B}\right)}{q t_{F}-q_{B} t_{B}}
$$

\section{Materials and Methods}

\section{Pilot-Plant Data}

Operating data was collected from a pilot-plant developed to treat effluent from a MBR at the Davis Station (Antarctica) Advanced Water Treatment Plant [29]. The data was collected during trial operation at Selfs Point, Hobart, Australia, with feed conditions set to mimic Davis Station. The plant has a maximum capability of $2.3 \times 10^{-4} \mathrm{~m}^{3} \mathrm{~s}^{-1}\left(20 \mathrm{~kL} \mathrm{~d}^{-1}\right)$ but operates in batch mode to achieve the desired daily output such that the operating feed rate is higher at $q=3.3 \times 10^{-4} \mathrm{~m}^{3} \mathrm{~s}^{-1}\left(20 \mathrm{~L} \mathrm{~min}^{-1}\right)$. In this plant, $0.1 \mu \mathrm{m}$ Metawater ceramic membranes $\left(A=25 \mathrm{~m}^{2}\right)$ are used as a micro-filter following ozonation of the wastewater, giving a specific flux of $48 \mathrm{~L} \mathrm{~m}^{-2} \mathrm{~h}^{-1}(\mathrm{LMH})$. Many MBRs operate in a cross-flow configuration with air sparging, but this case study the membrane units are external to the bioreactor and operated in dead end mode. A set volume of backwash $\left(0.1 \mathrm{~m}^{3}\right)$ was collected and the solids concentration of a sample was measured by weight loss on drying. A mass balance allowed estimation of the feed solids at 0.07 vol\% or $980 \mathrm{mg} / \mathrm{L}$. Operating data for the TMP was recorded at regular intervals at the pilot-plant for comparison with model predictions.

\section{Material Characterization}

Ideally, a backwash sample of the fouling layer from the pilot-plant would have been fully characterized using laboratory-scale gravity settling [23], centrifugation [22] and constant pressure filtration [5] tests. However, the high levels of shear experienced by the bio-fouling layer during backwash would have altered the dewatering properties. Also, given the low feed concentration, it was not possible to collect and concentrate enough feed to give enough sludge to do characterization testing. Instead, a representative sludge sample from a previous study [24] was used to approximate the material properties of the fouling. The sludge selected was an aerated anaerobic lagoon sludge with similar levels of digestion to the pilot-plant sludge. The experimental data from the representative sludge was fitted using Eq. (1) and (2) to provide an understanding of the compressibility and permeability of the filter cake. Based on previous sludge data [24] the compressibility factor, $p_{2}$, for wastewater treatment sludges is typically 2-4 and the coefficient $r_{n}$ is generally within the range $2-4$. The compressive strength and permeability functions were varied in these ranges to show the effect of these changes on the TMP rise, as detailed in Tab. 1. 
((Table 1))

All other fitting parameters remained constant; $\phi_{g}$ was 5 vol\%, $p_{1}$ was $0.88 \mathrm{kPa}, r_{a}$ was $8.6 \times 10^{16} \mathrm{~kg} \mathrm{~s}$ ${ }^{1} \mathrm{~m}^{-3}, r_{b}$ was $6.0 \times 10^{13} \mathrm{~kg} \mathrm{~s}^{-1} \mathrm{~m}^{-3}$ and $r_{g}$ was $-0.0025 \mathrm{v} / \mathrm{v}$. Prediction of filtration performance requires the complete functions for compressibility and permeability, not just $p_{2}$ and $r_{n}$. We vary these parameters simply to explore the role of compressibility and permeability of the filter cake on TMP rise and to highlight the conditions in which rapid TMP rise is most probable.

\section{Microfiltration Device Modeling}

The average initial solids concentration of the feed was calculated as $0.07 \mathrm{vol} \%$ and used as input into the model. The membrane resistance was calculated from operating data to be $2.4 \times 10^{9} \mathrm{~Pa} \mathrm{~s} \mathrm{~m}$ ${ }^{1}$ and the backwash time was $300 \mathrm{~s} . \phi_{0}, h_{0}, R_{m}, p_{y}(\phi), D(\phi)$ and $t_{B}$ were input into the constant flux filtration model and the numerical solution for TMP and solids concentration profiles were output.

\section{Optimization of Microfiltration Device Operation}

The optimization of operation was explored by modeling the effect of the main specified parameters; constant flux value and maximum TMP. These parameters influence the cycle times and frequency of backwashing. Constant flux operation for a wide range of fluxes from 1-200 LMH are simulated for the set maximum TMP values of 80,160 and $320 \mathrm{kPa}$. Values higher than $320 \mathrm{kPa}$ were not explored as this was the limiting value from design specifications.

\section{Results and Discussion}

\section{Material Characterization}

The equilibrium cake concentrations for the representative sludge were extracted from the laboratory constant pressure filtration and equilibrium centrifugation tests, and plotted against the applied pressure to give $p_{y}(\phi)$ (see Fig. $4(\mathrm{a})$ ). The variations in the compressibility factor, $p_{2}$, are also shown alongside their impact on the solids diffusivity (see Fig. 4(b)).

\section{((Figure 4))}

As $p_{2}$ increases, the compressibility is reduced. Consequently, a lower solids concentration is reached at a set applied pressure. The higher value for $\left(\mathrm{d} p_{y}(\phi) / \mathrm{d} \phi\right)$ is reflected by a higher $D(\phi)$. For most incompressible materials, such as coarse mineral suspensions, the gel point is much higher near close packing ( 0.64 for monodisperse spheres) and the $p_{y}(\phi)$ curve shifted to higher $\phi$. In general, these materials reach higher solids concentrations at lower applied pressures compared to wastewater treatment sludges. This usually results in a monotonically increasing $D(\phi)$ over the $\phi$ range of interest. Contrary to this behavior, sewage sludges exhibit $D(\phi)$ curves that are nonmonotonic or monotonically decreasing as shown in Fig. 4(b). This indicates that the rapid decrease in permeability is dominating the strengthening of the particulate network as $\phi$ increases [30]. The increase in $p_{2}$ shows the transition from a typical biological sludge $D(\phi)$ to curves more typical of a mineral processing suspension.

The permeability results from analysis of the cake compression region for the full range of constant pressure filtration tests are shown in Fig. 5(a). The analysis of the cake formation region using the method outlined in $\mathrm{Ng}$, et al. [31] gives a corresponding specific resistance to filtration (SRF) value of 
$1.34 \times 10^{13} \mathrm{~m} \mathrm{~kg}^{-1}$. The SRF was determined from the slope of the $t / V$ versus $V$ plot for a $50 \mathrm{kPa}$ constant pressure filtration test, assuming the dynamic viscosity of the filtrate, $\eta$, to be $0.001 \mathrm{~Pa} \mathrm{~s}$ and a solids density, $\rho_{s}$, of $1400 \mathrm{~kg} \mathrm{~m}^{-3}$.

A range of different curve fits to $R(\phi)$ are presented varying the parameter, $r_{\mathrm{n}}$, together with the resulting changes to $D(\phi)$ (see Fig. 5(b)). Increasing the permeability (increasing $r_{\mathrm{n}}$ ) results in a higher $D(\phi)$ and a more pronounced non-monotonic $D(\phi)$ curve. For $r_{\mathrm{n}}=5$, the initial strengthening of the filter cake has a greater effect than the permeability effects, but this trend is reversed as the resistance rapidly increases at around 20 vol\%.

((Figure 5))

The $R(\phi)$ curve fits can be converted to the mass specific cake resistance, $\alpha_{m}$, units of $\mathrm{m} \mathrm{kg}^{-1}$, using the derivation in de Kretser, et al. [32], as shown in Eq. (11):

$$
\alpha_{m}=\frac{R(\phi)}{(1-\phi)^{2} \rho_{s} \eta}
$$

The functional forms for $p_{y}(\phi)$ and $R(\phi)$ shown in Fig. 4(a) and Fig. 5(a) were converted to the specific cake resistance as a function of applied pressure difference (TMP). The effect of changing the biofouling compressibility, using $p_{2}$, and permeability, using $r_{n}$, is shown in Fig. 6(a) and Fig. $6(\mathrm{~b})$ respectively.

\section{((Figure 6))}

The impact of these permeability and compressibility changes on the predicted TMP rise is explored in the following sections.

\section{Effect of Compressibility and Permeability on TMP rise}

The effect of the variation in compressibility on the TMP rise for one constant flux filtration cycle is shown in Fig. 7(a). There is a clear trend with compressibility factor, $p_{2}$. The more compressible cases (lower $p_{2}$ ) show an increasingly rapid rise in TMP. A more compressible fouling layer results in higher solids concentrations at the membrane surface for the applied pressure required to maintain the flux at $48 \mathrm{LMH}$. This layer of higher solids concentration causes increased hydrodynamic resistance to filtration, which in turn increases the pressure required to maintain a constant flux. The observed result is a rapid increase in TMP. However, this modeling is unable to account for the discontinuity and sharp change in TMP observed in multiple studies [12, 33, 34]. A combination of compressibility effects, internal membrane fouling and inhomogeneous fouling models are required to fully capture this behavior.

\section{((Figure 7))}

The effect of the variation in permeability on the TMP rise for one cycle was also explored (see Fig. $7(b))$. The lower $r_{\mathrm{n}}$ and consequently lower permeability materials reduce the time to reach maximum TMP. As expected, more frequent cleaning is required for less permeable fouling layers.

The TMP rise is highly sensitive to changes in permeability and even a relatively small change in permeability factor from 3 to 2.84 (a 17\% decrease in permeability at 10 vol\%) can result in the need to backwash $15 \%$ earlier. Changing the permeability does not change the sharpness of the TMP 
jump, unlike the compressibility (see Fig. 7(a)), but the permeability is influential on the overall dewatering behavior.

\section{Comparison to Operating Data}

The operation of the pilot-plant microfiltration device was simulated using the compressible cake model with material properties as inputs, together with $q, \phi_{0}, h_{0}, R_{m}$ and $t_{B}$. The set point values for material properties detailed in Table 1 were selected. The TMP rise was also predicted using an incompressible cake model with the SRF, $q, \eta$ and the weight of solids per unit volume of filtrate, $c$, used as inputs. The results of the comparison between the simulation and operating data are presented in Fig. 8.

\section{((Figure 8))}

The incompressible model is unable to capture the non-linear rise in TMP. In contrast, the compressive rheology model predictions are a reasonable approximation of the operating data, but they are not able to capture the complete dewatering behavior of the bio-fouling layer. This is expected as material properties are only approximate and the errors on the calculation for feed concentration are high. The higher initial TMP after the third cycle was caused by incomplete removal of the fouling. This effect was modeled by specifying irreversible fouling layers of between 50-60 $\mu \mathrm{m}$.

The critical suction model [35] proposes an alternative explanation for the observed TMP jump. This model also indicates the importance of compressibility of the fouling layer with the suggestion of coagulation or collapse at the base of the filter cake [35, 36]. The observation of a thin, dense layer at the filter surface is consistent with other studies that have measured similar effects for extremely compressible materials, such as sewage sludge and fine colloidal suspensions [37-40]. Solids concentration profiles (of cell mass and extracellular polymeric substances, EPS) were observed by Hwang, et al. [41] during imaging of the fouling layer but not a critical coagulation event. This indicates that compression of the fouling layer is a continuous process that occurs as the applied pressure increases. From the compressive rheology modeling in Fig. 8, the predicted fouling layer depth at the end of each cycle was approximately $80 \mu \mathrm{m}$, which is similar to direct measurements for similar tests $[4,41]$. This predicted fouling layer thickness is based on numerical solution of the governing equation (Eq. 4) derived from volume and momentum balances. The compressive rheology framework has previously been able to predict the highly resistive "skin" at the membrane surface [42].

This case study involved a dead-end filtration process at high flux and low set maximum TMP conditions, which results in frequent backwash cycles. Under these conditions, the compressive rheological approach can predict the operating data without requiring alternative mechanisms, such as inhomogeneity. The model is also able to predict extended operation (days-weeks) under different operation conditions, such as lower feed concentration and a more permeable fouling layer. Shear forces are expected to reduce the solids reaching the membrane and even remove fouling, thus extending the time before TMP jump is observed.

\section{Optimization of Microfiltration Device Operation}

The optimization of cycle times, flux rates and maximum pressures through modeling was also briefly explored. The cycle time is dictated by the specified flux rate and maximum pressure. The effect of 
changing the flux rate and maximum TMP on the membrane area required to maintain an overall throughput of $3.3 \times 10^{-4} \mathrm{~m}^{3} \mathrm{~s}^{-1}$ is shown in Fig. 9 .

\section{((Figure 9))}

At low constant fluxes ( $<60 \mathrm{LMH})$ the required membrane size decreases rapidly as the flux increases for all three maximum TMP values. The behavior at these low fluxes is similar to the limiting behavior $\left(t_{F}>>t_{B}\right)$, which gives $A=Q / q$ from Eq. (10). Above $60 \mathrm{LMH}$, the ratio of filtration time $\left(t_{F}\right)$ to backwash time $\left(t_{B}\right)$ becomes important and the mode of operation can be optimized. The predictions suggest that the required filter area reaches a minimum when the filtration time is of a similar order of magnitude to the backwash time. For this case, the minimum area for a TMP $\max$ of $80 \mathrm{kPa}$ occurs at $90 \mathrm{LMH}$, which corresponds to $t_{F}=5 t_{B}$. The minimum area values for $160 \mathrm{kPa}$ and $320 \mathrm{kPa}$ occur when $t_{F}=3 t_{B}$ and $t_{F}=2 t_{B}$ respectively. The model indicates that the higher set values of the $\mathrm{TMP}_{\max }$ reduce the required filter size. However, this maximum pressure is restricted by pump size and membrane robustness. Irreversible fouling will also have a greater effect at higher fluxes, which is not accounted for in the optimization.

This optimization exercise highlights that there are limited benefits from operating at higher fluxes than the set value of $48 \mathrm{LMH}$. If the filters were designed to operate at fluxes higher than $60 \mathrm{LMH}$ then significantly larger membranes would be required. The simulations also demonstrate that at the design flux of $48 \mathrm{LMH}$, there is only minor improvements expected from increasing the $\mathrm{TMP}_{\max }$ to $320 \mathrm{kPa}$. The more conservative value of $160 \mathrm{kPa}$ (or below) also reduces irreversible fouling and promotes more sustainable operation.

\section{$\underline{\text { Model Limitations and Assumptions }}$}

Many simplifying assumptions were made to model the constant rate filtration process in the microfiltration device. For example, the model is simplified to a one-dimensional Cartesian coordinate system. As membranes are configured in many different geometries, such an approximation may not always be valid. The Cartesian coordinate system is most appropriate for flat sheet configurations and can be used for tubular membranes with reasonable accuracy, as shown by the current work. A radial coordinate system may be required for accurate modeling of hollow fiber membrane configurations, but only when the cake height becomes comparable to the curvature.

Another major assumption was that shear forces are negligible, so the errors may be significant if applying the model to high flowrate cross-flow filtration [43]. This does not affect the data presented here since the pilot-plant used for this study operated using dead-end filtration without aeration, so the shear forces experienced by the fouling layer were lower than for most submerged membrane units. Any model would need to incorporate the effect of shear stresses on the compressibility and permeability [44]. The one-dimensional model is used here because the theory has been developed and validated (for filtration with negligible shear), and a computationally feasible algorithm can be implemented.

The modeling of backwash operation can be further developed to account for the removal of fouling layer through shear or relaxation. If the shear yield stress of the sludge is measured and an estimate for the applied shear force can be made, then it is feasible for this to be included in subsequent modeling. This can be used to estimate the amount of the irreversible fouling after each cycle. The empirical backwash model presented by Jørgensen, et al. [45] is an alternative approach that can be incorporated. 
The model assumes a uniform height for the external fouling layer covering the membrane, but in practice the coverage of the fouling layer will be inhomogeneous. This inhomogeneity has been shown to cause TMP jump phenomena and would result in a more rapid increase in TMP compared to Fig. 9. Furthermore, macroscopic fouling with rags and other debris are not considered in the current model. This type of fouling and clogging can impact TMP rise and trigger the need for cleaning cycles.

A more advanced model for long-time operation must consider changes to the dewatering properties due to volatile solids destruction [24] and cell death at the membrane [41]. In this work, the cycle time of 3 hours is not enough time for biological activity to significantly affect the dewatering properties of the fouling through EPS production. Such an effect is also unlikely since filtration is preceded by an ozonation step with residual ozone often present at the membrane surface. Other studies have observed EPS accumulation, but at much longer time frames of operation [41]. The EPS concentration in the sludge has a strong impact on its dewatering behavior [24] and has been used as the basis for a model to predict the critical time at which the TMP jump occurs [46]. The EPS concentration and composition of the sludge varies significantly depending on a range of factors including sludge age, which influence the permeability and compressibility [31].

\section{Conclusions}

This work applied a compressive rheology framework to the modeling of wastewater effluent filtration in a ceramic microfilter. We showed that a rapid increase in TMP can be predicted for a highly compressible fouling layer that is external to the membrane surface. A combination of compressible filter cake modeling and the other mechanisms [12] proposed for TMP jump are required to model the discontinuity and sharp rise observed in other studies $[12,33,34]$.

The compressive rheology model prediction was compared to pilot-plant TMP data from a dead-end ceramic microfiltration membrane. The predictions and operating data show a reasonable level of agreement. The fouling layer is predicted to be extremely thin $(\sim 80 \mu \mathrm{m})$, which is of the same order of magnitude as physical measurement of similar fouling layers [41]. Optimization of flux rates and maximum pressures were performed using this model to guide the most sustainable operating practices. Further work is required to update the model to account for the influence of shear and to accurately capture backwash behavior.

\section{Acknowledgements}

An earlier version of this paper [47] was presented by the lead author at FILTECH2016 in Cologne, Germany, October 11-13, 2016. Adrian Knight is thanked for facilitating collection of bio-fouling sample in backwash from the Davis Station Advanced Water Treatment Plant. Michael Packer from the Australian Antarctic Division and Jianhua Zhang from Victoria University are also thanked for providing information and access to the pilot-plant. Daniel Green and the staff at Selfs Point Laboratory (TasWater) are acknowledged for sample testing. Samuel Skinner is supported by the Elizabeth and Vernon Puzey Scholarship and an Australian Government Research Training Program Scholarship. Infrastructure support was provided by the Particulate Fluids Processing Centre, a Special Research Centre of the Australian Research Council.

The authors have declared no conflict of interest. 
Symbols used

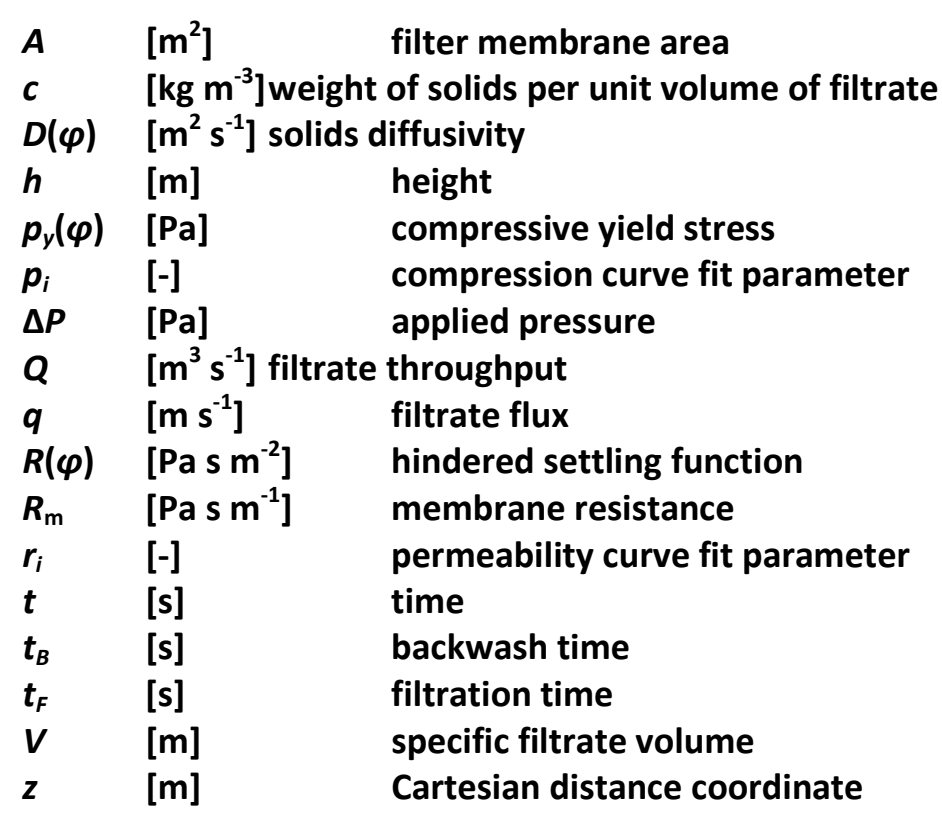

\section{Greek letters}

$\begin{array}{lll}\alpha_{m} & {\left[\mathrm{~m} \mathrm{~kg}^{-1}\right] \text { specific cake resistance (mass basis) }} \\ \eta & {[\mathrm{Pa} \mathrm{s}]} & \text { dynamic viscosity of fluid } \\ \phi & {[\mathrm{v} / \mathrm{v}]} & \text { solids volume fraction } \\ \phi_{\text {ave }} & {[\mathrm{v} / \mathrm{v}]} & \text { average solids volume fraction in the device } \\ \phi & {[\mathrm{v} / \mathrm{v}]} & \text { feed solids volume fraction } \\ \phi_{g} & {[\mathrm{v} / \mathrm{v}]} & \text { gel point solids volume fraction } \\ \rho_{s} & {\left[\mathrm{~kg} \mathrm{~m}^{-3}\right]} & \text { solids density }\end{array}$

\footnotetext{
Abbreviations

$L M H \quad$ typical unit of flux measurement $\left[\mathrm{L} \mathrm{m}^{-2} \mathrm{~h}^{-1}\right]$

MBR membrane bioreactor

SRF specific resistance to filtration $\left[\mathrm{m} \mathrm{kg}^{-1}\right]$

TMP transmembrane pressure
}

\section{References}

[1] M. K. Jørgensen, T. V. Bugge, M. L. Christensen, K. Keiding, J. Membrane Sci., Article, 2012, 409-410, 335-345. DOI: 10.1016/j.memsci.2012.04.002

[2] T. V. Bugge, M. K. Jørgensen, M. L. Christensen, K. Keiding, Water Res., 2012, 46 (14), 43304338. DOI: http://dx.doi.org/10.1016/j.watres.2012.06.015

[3] E. Poorasgari, T. V. Bugge, M. L. Christensen, M. K. Jørgensen, J. Membrane Sci., 2015, 475, 65-70. DOI: http://dx.doi.org/10.1016/j.memsci.2014.09.056

[4] N. Derlon, A. Grütter, F. Brandenberger, A. Sutter, U. Kuhlicke, T. R. Neu, E. Morgenroth, Water Res., 2016, 102 (Supplement C), 63-72. DOI: https://doi.org/10.1016/j.watres.2016.06.019 
[5] A. D. Stickland, C. Burgess, D. R. Dixon, P. J. Harbour, P. J. Scales, L. J. Studer, S. P. Usher, Chem. Eng. Sci., 2008, 63 (21), 5283-5290. DOI: 10.1016/j.ces.2008.07.016

[6] C. Duclos-Orsello, W. Li, C.-C. Ho, J. Membrane Sci., 2006, 280 (1-2), 856-866. DOI: http://dx.doi.org/10.1016/i.memsci.2006.03.005

[7] Z. B. Sendekie, P. Bacchin, Langmuir, 2016, 32 (6), 1478-1488. DOI: 10.1021/acs.langmuir.5b04218

[8] S. Judd, The MBR book: principles and applications of membrane bioreactors for water and wastewater treatment, Elsevier, 2010.

[9] A. Drews, J. Membrane Sci., 2010, 363 (1-2), 1-28. DOI: http://dx.doi.org/10.1016/j.memsci.2010.06.046

[10] Y. Ye, P. L. Clech, V. Chen, A. G. Fane, J. Membrane Sci., 2005, 264 (1-2), 190-199. DOI: http://dx.doi.org/10.1016/j.memsci.2005.04.040

[11] S. Ognier, C. Wisniewski, A. Grasmick, Membr. Tech., Article, 2002, (147), 6-10. DOI: http://dx.doi.org/10.1016/S0958-2118(02)07018-0

[12] B. D. Cho, A. G. Fane, J. Membrane Sci., 2002, 209 (2), 391-403. DOI: http://dx.doi.org/10.1016/S0376-7388(02)00321-6

[13] A. Yeo, A. G. Fane, Water Sci. Technol., 2005, 51 (6-7), 165-172.

[14] B.-K. Hwang, C.-H. Lee, I.-S. Chang, A. Drews, R. Field, J. Membrane Sci., 2012, 419-420, 3341. DOI: http://dx.doi.org/10.1016/i.memsci.2012.06.031

[15] S. W. Hermanowicz. Membrane filtration of biological solids: a unified framework and its applications to MBR, IWA Publishing, Seoul, Korea, 2004.

[16] K. Keiding, N. D. Jensens. Effects of Compressibility on MBR Sludge Filtration, Gratz, Austria, 2012.

[17] M. K. Jørgensen, K. Keiding, M. L. Christensen, J. Membrane Sci., Article, 2014, 455, 152-161. DOI: 10.1016/j.memsci.2013.12.052

[18] B. L. Sørensen, P. B. Sorensen, Water Res., 1997, 31 (3), 665-670. DOI: http://dx.doi.org/10.1016/S0043-1354(96)00283-7

[19] F. Tiller, M. Shirato, AlChE J., 1964, 10 (1), 61.

[20] M. K. Jørgensen, E. Kujundzic, A. R. Greenberg, Desalin. Water Treat., 2016, 57 (14), 61596171. DOI: 10.1080/19443994.2015.1005695

[21] K. A. Landman, C. Sirakoff, L. R. White, Phys. Fluids A-Fluid, 1991, 6, 1495-1509. DOI: http://dx.doi.org/10.1063/1.857986

[22] R. Buscall, L. R. White, J. Chem. Soc. Farad. T. 1, 1987, 83 (3), 873-891. DOI: http://dx.doi.org/10.1039/f19878300873

[23] D. R. Lester, S. P. Usher, P. J. Scales, AlChE J., 2005, 51 (4), 1158-1168. DOI: 10.1002/aic.10333

[24] S. J. Skinner, L. J. Studer, D. R. Dixon, P. Hillis, C. A. Rees, R. C. Wall, R. G. Cavalida, S. P. Usher, A. D. Stickland, P. J. Scales, Water Res., 2015, 82, 2-13. DOI: http://dx.doi.org/10.1016/j.watres.2015.04.045

[25] A. D. Stickland, R. G. de Kretser, A. R. Kilcullen, P. J. Scales, P. Hillis, M. R. Tillotson, AlChE J., 2008, 54 (2), 464-474. DOI: 10.1002/aic.11369

[26] A. D. Stickland, R. G. de Kretser, P. J. Scales, S. P. Usher, P. Hillis, M. R. Tillotson, Chem. Eng. Sci., 2006, 61, 3818 - 3829. DOI: http://dx.doi.org/10.1016/j.ces.2006.01.020

[27] A. D. Stickland, R. G. De Kretser, P. J. Scales, AlChE J., 2005, 51 (9), 2481-2488. DOI: 10.1002/aic.10501

[28] S. P. Usher, L. J. Studer, R. C. Wall, P. J. Scales, Chem. Eng. Sci., 2013, 93, 277-291. DOI: 10.1016/j.ces.2013.02.026

[29] J. Zhang, A. Knight, M. Duke, K. Northcott, M. Packer, P. J. Scales, S. R. Gray, Process. Saf. Environ., 2016, 104, Part A, 196-208. DOI: http://dx.doi.org/10.1016/i.psep.2016.08.017 
[30] D. R. Hewitt, D. T. Paterson, N. J. Balmforth, D. M. Martinez, Phys. Fluids, 2016, 28 (6), 063304. DOI: doi:http://dx.doi.org/10.1063/1.4952582

[31] H. Y. Ng, S. W. Hermanowicz, Water Environ. Res., 2005, 77 (2), 187-192. DOI: $10.2175 / 106143005 \times 41753$

[32] R. G. de Kretser, P. J. Scales, D. V. Boger, in Rheology Reviews 2003, (Eds: D. M. Binding, K. Walters), British Society of Rheology, Aberystwyth, 2003, 125-166.

[33] W.-W. Li, G.-P. Sheng, Y.-K. Wang, X.-W. Liu, J. Xu, H.-Q. Yu, Sep. Purif. Technol., 2011, 81 (3), 472-479. DOI: http://dx.doi.org/10.1016/j.seppur.2011.08.026

[34] P. Le-Clech, V. Chen, T. A. G. Fane, J. Membrane Sci., 2006, 284 (1-2), 17-53. DOI: http://dx.doi.org/10.1016/j.memsci.2006.08.019

[35] S. Chang, T. Fane, T. Waite. Effect of coagulation within the cake layer on fouling transitions with dead-end hollow fiber membranes, Vol. 2126 (in series), Seoul, Korea, 2005.

[36] S. Chang, A. G. Fane, T. D. Waite, J. Membrane Sci., 2006, 268 (2), 132-141. DOI: http://dx.doi.org/10.1016/j.memsci.2005.06.010

[37] E. J. La Heij, P. J. A. M. Kerkhof, K. Kopinga, L. Pel, AlChE J., Journal Article, 1996, (4), 953. DOI: 10.1002/aic.690420408

[38] J. T. Novak, M. L. Agerbaek, B. L. Sorensen, J. A. Hansen, J. Environ. Eng., 1999, 125 (9), 816824. DOI: http://dx.doi.org/10.1061/(ASCE)0733-9372(1999)125:9(816)

[39] H. Saveyn, D. Curvers, L. Pel, P. De Bondt, P. Van der Meeren, Water Res., 2006, 40 (11), 2135-2142. DOI: http://dx.doi.org/10.1016/j.watres.2006.04.003

[40] F. M. Tiller, T. C. Green, AlChE J., 1973, 19 (6), 1266-1269. DOI: 10.1002/aic.690190633

[41] B.-K. Hwang, W.-N. Lee, K.-M. Yeon, P.-K. Park, C.-H. Lee, i.-S. Chang, A. Drews, M. Kraume, Environ. Sci. Technol., 2008, 42 (11), 3963-3968. DOI: 10.1021/es7029784

[42] A. D. Stickland, Water Res., 2015, 82, 37-46. DOI: http://dx.doi.org/10.1016/i.watres.2015.04.004

[43] M. Davey, K. Landman, J. M. Perera, G. W. Stevens, N. D. Lawrence, M. Iyer, AlChE J., 2004, 50 (7), 1431-1437. DOI: 10.1002/aic.10136

[44] A. D. Stickland, R. Buscall, J. Non-Newt. Fluid Mech., 2009, 157 (3), 151-157. DOI: http://dx.doi.org/10.1016/i.jnnfm.2008.11.006

[45] M. K. Jørgensen, T. V. Bugge, B. H. Hede, M. L. Christensen. A model to describe removal of fouling during relaxation, Taipei, Taiwan, 2016.

[46] D. P. Saroj, G. Guglielmi, D. Chiarani, G. Andreottola, Desalination, 2008, 231 (1), 175-181. DOI: http://dx.doi.org/10.1016/i.desal.2007.11.045

[47] S. J. Skinner, A. D. Stickland, P. J. Scales. Compressive Rheology of Biofouling: Application to Membrane Bioreactors, Cologne, Germany, 2016.

\section{Collection of figure legends}

Figure 1. Schematic of proposed mechanism for rapid increase in TMP caused by compression of fouling layer.

Figure 2. Schematic of the stages of operation of a microfiltration device including the (a) constant flux operation and (b) backwash to remove bio-fouling layer.

Figure 3. Schematic of one-dimensional filtration under constant flux $q$ operation with a feed volume fraction $\phi_{0}$ below the gel point $\phi_{\mathrm{g}}$. The transmembrane pressure $\Delta P(t)$ and fouling layer height $z_{c}(t)$ increase with time $t$. Region (1): membrane, $z=0$; Region (2): fouling layer, $0<z<z_{c}(t)$; Region (3): sludge at feed concentration, $z_{c}(t)<z<h_{0}$. At $z_{c}(t), \phi=\phi_{g}$. 
Figure 4. (a) Compressive strength, $p_{y}(\phi)$, variation and impact on (b) solids diffusivity, $D(\phi)$, for a consistent $R(\phi)=8.6 \times 10^{16}(\phi-0.0025)^{2.87}+6.0 \times 10^{13}$. Data points are from the characterization of a representative sludge sample.

Figure 5. (a) The hindered settling function, $R(\phi)$, variation and impact on (b) solids diffusivity, $D(\phi)$, for a consistent $p_{y}(\phi)=0.88\left((\phi / 0.05)^{2.84}-1\right)$. Data points are from the characterization of a representative sludge sample.

Figure 6. The variations in (a) compressive strength, and (b) hindered settling function converted into the classical definition of compressibility. Data points are from the characterization of a representative sludge sample.

Figure 7. Model predictions for the transmembrane pressure (TMP) rise with variations in the (a) the compressibility and (b) the permeability of the membrane fouling layer for a constant flux of $48 \mathrm{LMH}$, $R_{m}=2.4 \times 10^{9} \mathrm{~m}^{-1}, \phi_{0}=0.007 \mathrm{vol} \%$ and $h_{0}=1.0 \mathrm{~m}$.

Figure 8. Comparison of operating data from the pilot-plant developed to treat wastewater effluent and compressive rheology model predictions from permeability and compressibility functional forms for (a) ten complete backwash cycles between chemical cleaning and (b) a close-up of the first three backwash cycles.

Figure 9. Modeling predictions for the required filter membrane area, $A$, required to maintain a throughput, $Q=20 \mathrm{~L} \mathrm{~min}^{-1}$ for four specified maximum TMPs over a range of constant fluxes, $q$.

\section{Tables and table legends}

Table 1. Material property parameter values for compressibility $p_{2}$ and permeability $r_{n}$ and set points for exploring the impact of compressibility and permeability on the TMP rise in a microfiltration device.

\begin{tabular}{llll}
\hline Parameter & Units & Values & Set point \\
\hline$p_{2}$ & {$[-]$} & $1,2,2.84,3,4,5$ & 2.84 \\
$r_{n}$ & {$[-]$} & $1,2,2.87,3,4,5$ & 2.87 \\
\hline
\end{tabular}

\section{Table of contents text}

This study investigates the compressive behavior of the bio-fouling layer in wastewater filtration and its impact on transmembrane pressure (TMP) rise in controlled rate processes. The high compressibility of the external fouling is shown to cause rapid TMP increase. A 1D filtration model is proposed to predict the rise in TMP required for constant flux. Model predictions were compared to pilot-plant data and showed good agreement. 


\section{University Library}

\section{- M M I E E R VA A gateway to Melbourne's research publications}

Minerva Access is the Institutional Repository of The University of Melbourne

Author/s:

Skinner, SJ;Stickland, AD;Scales, PJ

Title:

Predicting Transmembrane Pressure Rise from Biofouling Layer Compressibility and Permeability

Date:

2018-01-01

Citation:

Skinner, S. J., Stickland, A. D. \& Scales, P. J. (2018). Predicting Transmembrane Pressure Rise from Biofouling Layer Compressibility and Permeability. CHEMICAL ENGINEERING \& TECHNOLOGY, 41 (1), pp.51-60. https://doi.org/10.1002/ceat.201700117.

Persistent Link:

http://hdl.handle.net/11343/294027 